\title{
Protective effects of glutamine in a rat model of endotoxemia
}

\author{
YA-JUAN ZHAO ${ }^{1}$, HONG WANG $^{1}$, XIN LIU $^{1}$, MEI SUN $^{1}$ and HAGINOYA KAZUHIRO ${ }^{2}$ \\ ${ }^{1}$ Department of Pediatrics, Shengjing Hospital of China Medical University, Shenyang, Liaoning 110004, P.R. China; \\ ${ }^{2}$ Department of Pediatric Neurology Takuto Rehabilitation Center for Children, Sendai 982-0241, Japan
}

Received February 7, 2012; Accepted July 20, 2012

DOI: $10.3892 / \mathrm{mmr} .2012 .1007$

\begin{abstract}
The aim of this study was to characterize the protective effects of glutamine (Gln) on brain cells undergoing experimental endotoxemia induced by lipopolysaccharide (LPS) injection. Young rats were injected with LPS or control, and a subset of LPS-injected rats were pretreated with Gln. Electron microscopy and immunohistochemistry were used to visualize apoptosis and to determine distribution and expression of nuclear factor- $\kappa \mathrm{B}(\mathrm{NF}-\kappa \mathrm{B})$, heat shock protein 70 (HSP70), platelet-derived growth factor-B (PDGF-B) and PDGF receptor- $\beta$ (PDGFR- $\beta$ ). The levels of HSP70, PDGF-B and PDGFR- $\beta$ in the rat brain were comparatively analyzed by western blotting. In a rat brain model of endotoxemia, GIn decreases the magnitude of apoptosis, upregulates the expression of HSP70 and inhibits the translocation of NF- $\kappa \mathrm{B}$ from the cytoplasm to the nucleus. Gln upregulates PDGF-B and PDGFR- $\beta$ expression in early and advanced sepsis. PDGF-B and PDGFR- $\beta$ upregulation in the cerebral cortex are likely neuroprotective effects of Gln. We found that Gln is capable of regulating the immunological defense of local brain tissue, which provides a theoretical basis for using Gln to prevent and treat encephalopathy.
\end{abstract}

\section{Introduction}

Endotoxemia presents a serious threat to pediatric critical care settings, as this illness may rapidly progress to multiple organ failure and ultimately to death. The mortality rate of endotoxemia is very high. However, the pathophysiology regarding the effects of endotoxemia on the central nervous system (CNS) remains poorly characterized. The enhanced expression of heat shock protein (HSP) is protective against septic shock in laboratory models (1). The inducible HSP isoforms (HSP70 and HSP27) are believed to confer cellular protection. Previous

Correspondence to: Dr Ya-Juan Zhao, Department of Pediatrics, Shengjing Hospital of China Medical University, Shenyang, Liaoning 110004, P.R. China

E-mail: zhaoyj87@163.com

Key words: glutamine, endotoxemia, lipopolysaccharide, apoptosis, nuclear factor- $\kappa \mathrm{B}$, heat shock protein, platelet-derived growth factor, brain studies using laboratory models of sepsis, ischemia-reperfusion or acute lung injury have suggested that these disorders may be significantly attenuated or prevented by the enhanced expression of HSPs (2-4). In vitro and in vivo models have reported that HSP expression suppresses plasma concentrations of proinflammatory cytokines (5). HSP70 has been reported to inhibit the activation of nuclear factor $-\kappa \mathrm{B}(\mathrm{NF}-\kappa \mathrm{B})$, a family of transcription factors that activate target genes involved in inflammation, the immune response and cell apoptosis (6). HSP70 exerts this effect by inducing $\mathrm{I} \kappa \mathrm{B} \alpha$, the inhibitor of $\mathrm{NF}-\kappa \mathrm{B}(7,8)$.

The nonessential amino acid glutamine (Gln) enhances the in vitro survival of cells. Platelet-derived growth factor (PDGF) functions in the development and regulation of the nervous system $(9,10)$. PDGF is upregulated in the hypoxic-ischemic neonatal rat brain (11). The expression levels of PDGF and its receptor following endotoxemic brain damage have not been examined.

To characterize the protective effect of Gln following endotoxemic brain damage, particularly in the young brain, we developed an endotoxemia model by injecting Wistar rats intraperitoneally with lipopolysaccharide (LPS) 10 days after birth (12). The expression of NF- $\kappa \mathrm{B}, \mathrm{HSP} 70$, platelet-derived growth factor-B (PDGF-B) and PDGF receptor- $\beta$ (PDGFR- $\beta$ ) in brain cells was examined by immunohistochemistry and western blotting. In addition, brain cell ultrastructure was examined for apoptosis. Comparative analyses were performed between animals receiving intraperitoneal LPS injection with or without prior Gln administration. This study preliminarily supports the use of Gln therapy for treatment of various infantile brain diseases, particularly ischemic and septic brain diseases.

\section{Materials and methods}

Animals and reagents. Healthy, 10-day-old male and female Wistar rats (mass $22.3 \pm 3.1 \mathrm{~g}$ ) were provided by the Animal Center of the Shengjing Hospital of China Medical University. N-(2)-L-alanine-L Gln (20\%), containing 13.46\% L-Gln, was purchased from Fresenius (Germany). Rabbit anti-rat HSP70 antibody was obtained from Santa Cruz Biotechnology (Santa Cruz, CA, USA). Rabbit anti-rat NF- $\mathrm{B}$, PDGF-B, and PDGFR- $\beta$ antibodies and $\mathrm{ABC}$ kits were purchased from Boster (Wuhan, China). LPS (E. coli $\mathrm{O}_{55}: \mathrm{B}_{5}$ ) powder, $\alpha$-dianisidine, $\beta$-naphthyl acid phosphate and hydroxybenzene were purchased from Sigma (St. Louis, MO, USA). The study 
was approved by the Ethics Committee of Shengjing Hospital of China Medical University.

Rat model of endotoxemia and tissue preparation. Wistar rats were divided randomly into the control, LPS and treatment groups.Control rats were intraperitoneally injected with $1 \mathrm{ml} / \mathrm{kg}$ of $0.9 \%$ sodium chloride, the same injection volume as the other groups. LPS group rats were intraperitoneally injected with a single $5 \mathrm{mg} / \mathrm{kg}$ bolus of LPS. Treatment group rats were injected with single boluses each of Gln and LPS, such that $1 \mathrm{ml} / \mathrm{kg}$ solution of $\mathrm{Gln}(1.346 \mathrm{~g} / \mathrm{kg})$ was administered intraperitoneally $1 \mathrm{~h}$ prior to LPS injection. Rats were fed after injection and were sacrificed at the indicated times. Cerebral tissues were then harvested. The cutting point was selected as the junction of the optic chiasm, the middle of premamillaris and the rear of the cerebrum and cerebellum. Fifteen rats from each group were used for western blotting. Three rats in each group were sacrificed 2, 6, 12, 24 and $72 \mathrm{~h}$ after the injection and cerebra were obtained. Remaining brain tissues were preserved at $-70^{\circ} \mathrm{C}$ for additional protein analyses. For immunohistochemistry and electron microscopy, 8 rats from each group were terminated 2, 6 and $72 \mathrm{~h}$ post-injection. Brains were divided into 4 sections and immediately fixed in $40 \mathrm{~g} / \mathrm{l}$ formaldehyde for $24 \mathrm{~h}$. Samples then were embedded in paraffin for immunohistochemistry. For electron microscopy, a coronal block $\left(1 \mathrm{~mm}^{3}\right)$ of the rat brain was excised at $4^{\circ} \mathrm{C}$ and fixed in 2.5\% paraformaldehyde solution for $2 \mathrm{~h}$.

Electron microscopy. Following fixation, blocks were washed with dimethyl arsenate buffer, fixed in $1 \%$ osmium tetroxide for $60 \mathrm{~min}$ and dehydrated in ascending concentrations of ethanol. Samples then were passed into propylene oxide and embedded in Epon 812 epoxy resin. After 72 h, 60-80 nm ultra-thin sections were made using a microtome and were stained with 5-uranyl acetate and lead citrate. Sections were examined with a Hitachi H-600 transmission electron microscope.

Immunolocalization of NF- $\kappa B, H S P 70, P D G F-B$ and $P D G F R-\beta$. Transverse sections $(6 \mu \mathrm{m})$ of brain were immunohistochemically stained for the detection of NF- $\mathrm{\kappa B}(1: 800)$, HSP70 (1:100), PDGF-B (1:75) and PDGFR- $\beta$ (1:150). Indirect immunoperoxidase (i.e., $\mathrm{ABC}$ ) methods were used. For $\mathrm{ABC}$ reactions, sections were immersed in $3 \mathrm{ml} / 1 \mathrm{H}_{2} \mathrm{O}_{2}$ for $15 \mathrm{~min}$ at $37^{\circ} \mathrm{C}$ and were washed in PBS. Samples then were incubated for $24 \mathrm{~h}$ at $4^{\circ} \mathrm{C}$ in the primary antibody and in biotinylated anti-rabbit IgG diluted 1:200 for $1 \mathrm{~h}$. Samples were incubated for $15 \mathrm{~min}$ at $37^{\circ} \mathrm{C}$ in the $\mathrm{ABC}$ complex and were visualized in $0.03 \%$ diaminobenzidine containing $0.005 \%$ peroxide. The specificity of immunostaining was confirmed by replacing the primary antibody with nonimmune normal rabbit serum, which resulted in total abolishment of immunoreactivity.

Western blotting for HSP70, PDGD-B and PDGFR- $\beta$. Three cerebra from each group were homogenized in lysis buffer containing $20 \mathrm{mmol} / 1$ Tris- $\mathrm{HCl}(\mathrm{pH} 7.5), 10 \mathrm{ml} / 1$ Triton, $0.2 \mathrm{~mol} / \mathrm{l} \mathrm{NaCl}, 2 \mathrm{mmol} / \mathrm{l}$ EDTA, $2 \mathrm{mmol} / \mathrm{l}$ EGTA, $1 \mathrm{~mol} / \mathrm{l}$ DTT and $2 \mathrm{~mol} / \mathrm{l}$ aprotinin. Samples were centrifuged at 12,000 x g for $1 \mathrm{~h}$ at $4^{\circ} \mathrm{C}$. Equal amounts of brain protein samples $(50 \mu \mathrm{g})$ were diluted in SDS incubation medium (100 mmol/l Tris-Cl (pH 6.8), $200 \mathrm{mmol} / \mathrm{l}$ DTT, $40 \mathrm{ml} / \mathrm{l} \mathrm{SDS}, 2 \mathrm{ml} / \mathrm{l}$ bromo-
A

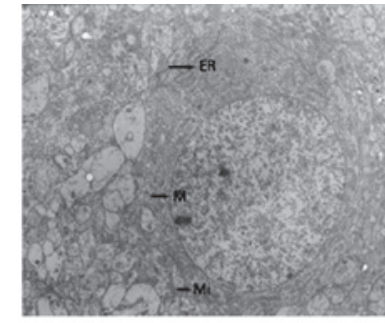

C

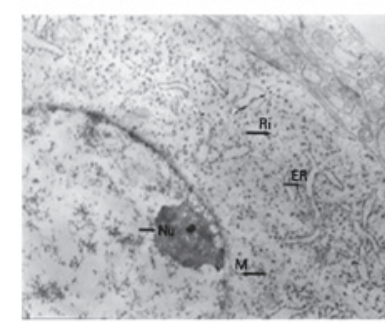

$\mathbf{E}$

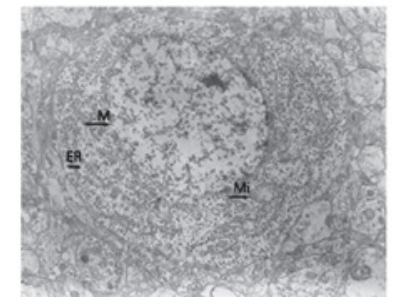

B

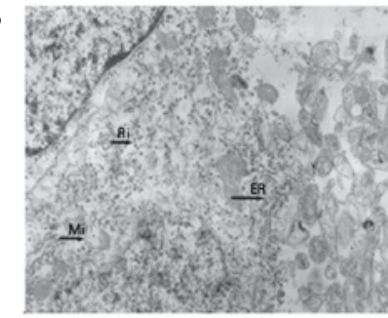

D

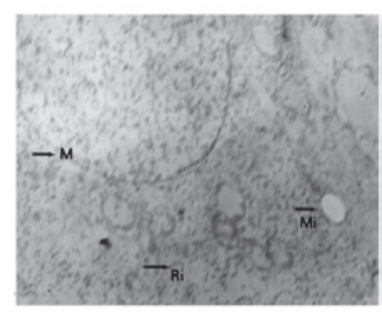

Figure 1. Neurons visualized by electron microscopy at various magnifications during the process of lipopolysaccharide (LPS)-induced apoptosis. (A) Normal neuron, $x 4,000$. (B) Early apoptosis in neuron $2 \mathrm{~h}$ after LPS injection, $x 10,000$. (C) Medium-term apoptosis in neuron $6 \mathrm{~h}$ after LPS injection, $\mathrm{x} 10,000$. (D) Advanced apoptosis in neuron $72 \mathrm{~h}$ after LPS injection, $\mathrm{x} 10,000$. (E) Neuron $72 \mathrm{~h}$ after LPS injection in glutamine (Gln) treatment group, $\mathrm{x} 5,000$.

phenol blue and $200 \mathrm{ml} / \mathrm{l}$ glycerol) and were applied to $0.8 \%$ SDS-PAGE. Samples were electrophoresed at $100 \mathrm{~V}$ for $1 \mathrm{~h}$. Proteins then were transferred onto nitrocellulose at $50 \mathrm{~V}$ and $4^{\circ} \mathrm{C}$ for $2 \mathrm{~h}$. After blocking with $50 \mathrm{ml} / \mathrm{l}$ non-fat dry milk in PBST [PBS ( $\mathrm{pH} 7.4), 0.1 \%$ Tween-20] for $1 \mathrm{~h}$, nitrocellulose blots were incubated overnight in primary antibody [anti-HSP70 (1:200), anti-PDGD-B (1:200), or anti-PDGFR- $\beta$ (1:200)] and were then incubated with alkaline phosphatase-conjugated goat antirabbit IgG (1:2000; Chemicon, Temecula, CA, USA) for $2 \mathrm{~h}$. Immunoreactive proteins were visualized using alkaline phosphatase. The images were analyzed using imaging software. A comparison of the LPS and treatment groups was expressed in terms of the relative protein content $(\%)$, which was determined as the gray value of the protein strip in sample/gray value of protein strip in the control $\times 100 \%$.

Statistical analysis. Data were analyzed by Student's t-test using SPSS 12.0. All data are expressed as the means \pm SD for each group. $\mathrm{P}<0.05$ was considered to indicate a statistically significant difference.

\section{Results}

Electron microscopic analysis. The neurocytes of control rats were characterized by discrete nuclear structures with evenly distributed chromatin, prominent nucleoli and intact nuclear membranes. Golgi apparatus and rough endoplasmic reticula were distributed loosely with ribosomes attached to the surface. Mitochondria were clearly visible with inner 
Table I. Semiquantitative expression of HSP70 in each group $(\bar{\chi} \pm s, n=3)$.

\begin{tabular}{|c|c|c|c|c|c|}
\hline Group & $2 \mathrm{~h}$ & $6 \mathrm{~h}$ & $12 \mathrm{~h}$ & $24 \mathrm{~h}$ & $72 \mathrm{~h}$ \\
\hline LPS & $1.05 \pm 0.04$ & $1.04 \pm 0.05$ & $0.72 \pm 0.04$ & $0.61 \pm 0.03$ & $0.92 \pm 0.03$ \\
\hline Gln & $1.83 \pm 0.02$ & $1.20 \pm 0.03$ & $1.03 \pm 0.08$ & $0.85 \pm 0.02$ & $1.01 \pm 0.07$ \\
\hline $\mathrm{T}$ & 9.51 & 4.75 & 6.01 & 11.54 & 2.05 \\
\hline P-value & $<0.01$ & $<0.01$ & $<0.01$ & $<0.01$ & $>0.05$ \\
\hline
\end{tabular}

HSP70, heat shock protein 70; LPS, lipopolysaccharide; Gln, glutamine.
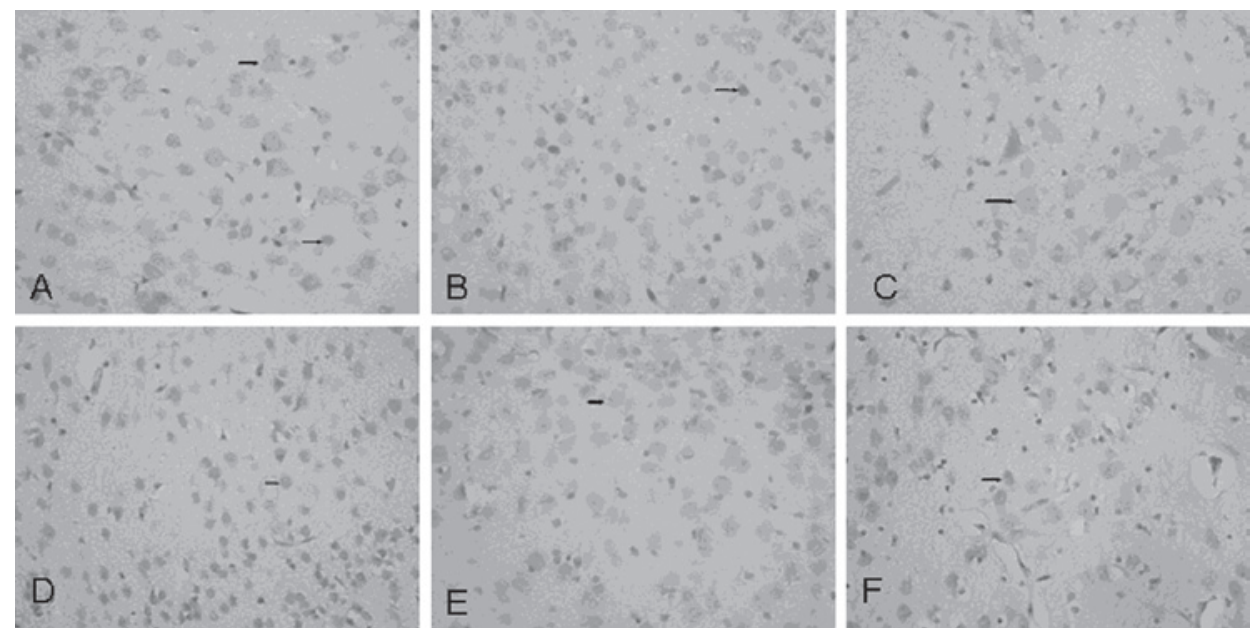

Figure 2. Immunolocalization of nuclear factor- $\kappa \mathrm{B}(\mathrm{NF}-\kappa \mathrm{B})$ and heat shock protein 70 (HSP70) in brain tissue. (A-C) NF- $\mathrm{B}$ and (D-F) HSP70 for $(\mathrm{A}, \mathrm{D})$ control and $(\mathrm{B}, \mathrm{E})$ lipopolysaccharide (LPS) groups at $6 \mathrm{~h}$ and $(\mathrm{C}, \mathrm{F})$ treatment group at $2 \mathrm{~h}$. NF-kB immunoreactivity was observed in the cytoplasm of neurons and was prominent in the nucleoli of LPS-group tissues. HSP70 immunoreactivity was observed in the nucleoli of cortical neurons.

cristae (Fig. 1A). At $2 \mathrm{~h}$ post-injection with LPS, nascent apoptosis was observed with significant swelling of nerve cells, shrunken nuclear membranes, irregular arrangements of endoplasmic reticula and degranulated ribosomes (Fig. 1B). At $6 \mathrm{~h}$ post-injection with LPS, the extent of apoptosis was more pronounced. Nerve cells exhibited chromatin condensation and nucleolar margination (Fig. 1C). At $72 \mathrm{~h}$, advanced apoptosis was observed with prominent nuclear fragmentation and with mitochondria displaying vacuolar degeneration, defective cristae and decreased matrix density (Fig. 1D). Near normal neurons were observed in the Gln treatment group $72 \mathrm{~h}$ after LPS injection. Nuclear membranes, nucleoli and mitochondrial structures were visible. Endoplasmic reticula were moderately swollen and irregularly arranged.

Immunolocalization of $N F-\kappa B$ and HSP70 in brain tissue. Anti-NF- $\kappa B$ antibody faintly stained the nuclei of control nerve cells (Fig. 2A). At 2-6 h after LPS injection (LPS group), increased NF- $\mathrm{KB}$ immunoreactivity was observed in the nuclei of several cortical neurons; immunoreactivity was more distinct at $6 \mathrm{~h}$ (Fig. 2B). At $2 \mathrm{~h}$ post-injection with LPS, NF-kB immunoreactivity could barely be observed in the nuclei of Gln-treated nerve cells (Fig. 2C).

In control brain tissue, HSP70 immunoreactivity was observed in the nucleoli of cortical neurons (Fig. 2D). Two hours after LPS injection, the number of positively stained neuronal cells decreased in the LPS group compared to controls (data

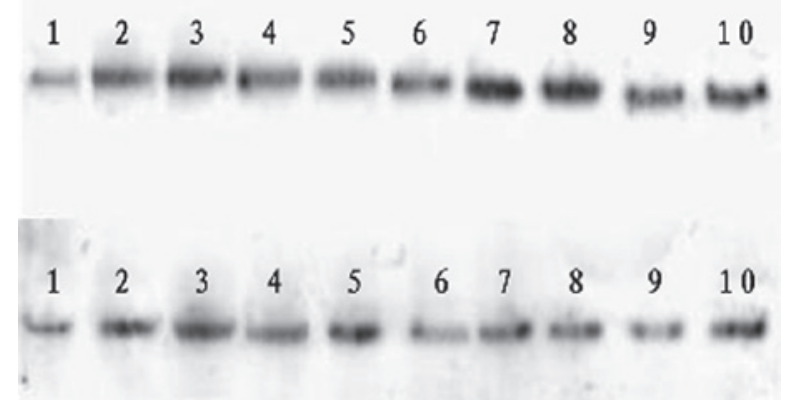

Figure 3. Western blot analysis of heat shock protein 70 (HSP70) protein expression at various time points following lipopolysaccharide (LPS) injection. Upper row depicts the control group from left to right as 1-5 (2, 6, 12, 24 and $72 \mathrm{~h}$ ) and the treatment group as 6-10 (2, 6, 12, 24 and $72 \mathrm{~h})$. Lower row depicts the control group from left to right as $1-5(2,6,12,24$ and $72 \mathrm{~h})$ and the LPS group as 6-10 (2, 6, 12, 24 and $72 \mathrm{~h})$.

not shown). HSP70 immunoreactivity was decreased further in LPS group brain samples $6 \mathrm{~h}$ after the injection (Fig. 2E). In the Gln treatment group, intense HSP70 immunoreactivity was observed in the nucleoli of cortical neurons $2 \mathrm{~h}$ after LPS injection as compared to the LPS group (Fig. 2F).

Western blot analysis of HSP70 protein expression following LPS injection. Brain tissues from the LPS group maintained relatively constant HSP70 levels at 2 and $6 \mathrm{~h}$ post-injection (Fig. 3, Table I). HSP70 expression decreased $12 \mathrm{~h}$ after 

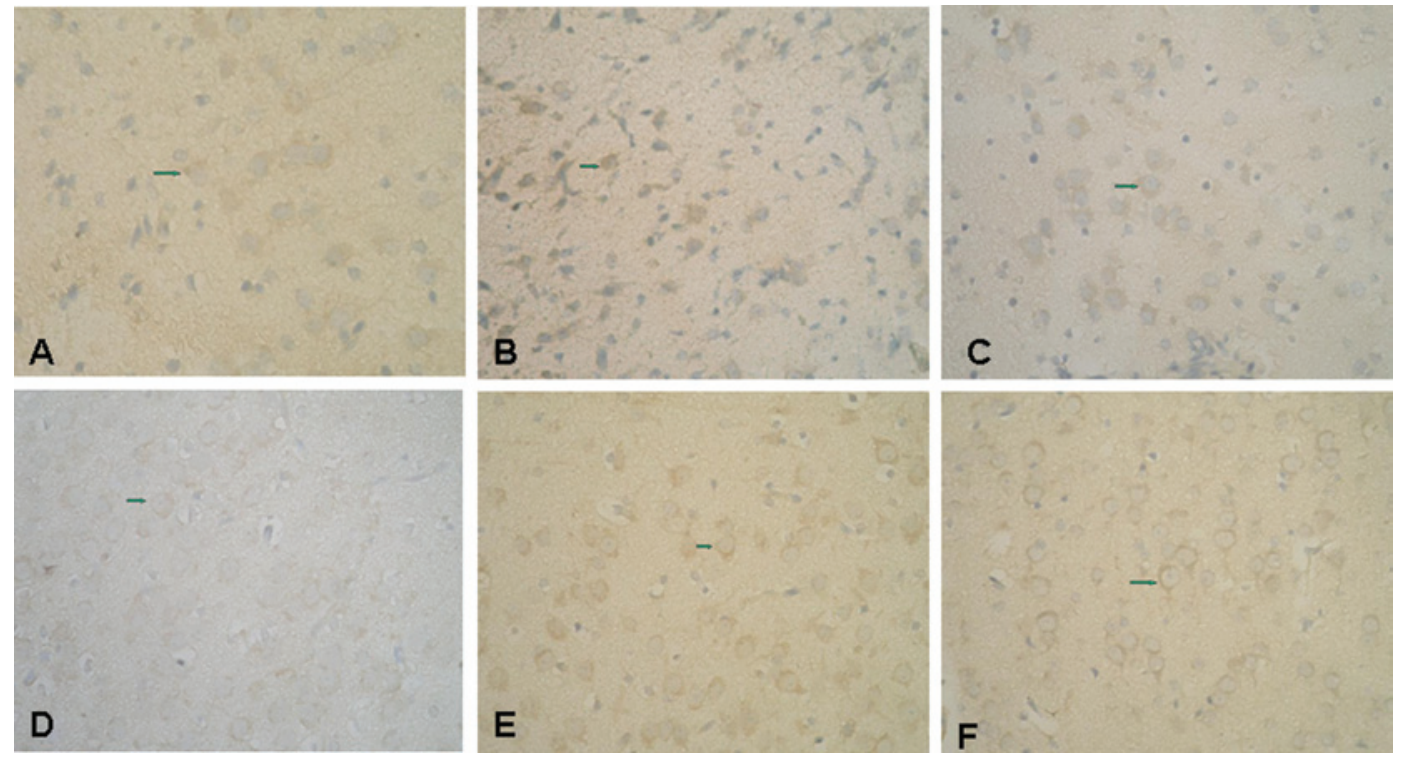

Figure 4. Immunolocalization of (A-C) platelet-derived growth factor-B (PDGF-B) and (D-F) PDGF receptor- $\beta$ (PDGFR- $\beta$ ) in brain tissue of (A,D) controls, (B,E) lipopolysaccharide (LPS) group at $72 \mathrm{~h}$, and the (C,F) glutamine (Gln) treatment group at $72 \mathrm{~h}$. PDGF-B immunoreactivity was observed in the cytoplasm, PDGFR- $\beta$ immunoreactivity was observed in the membrane of cortical neurons.

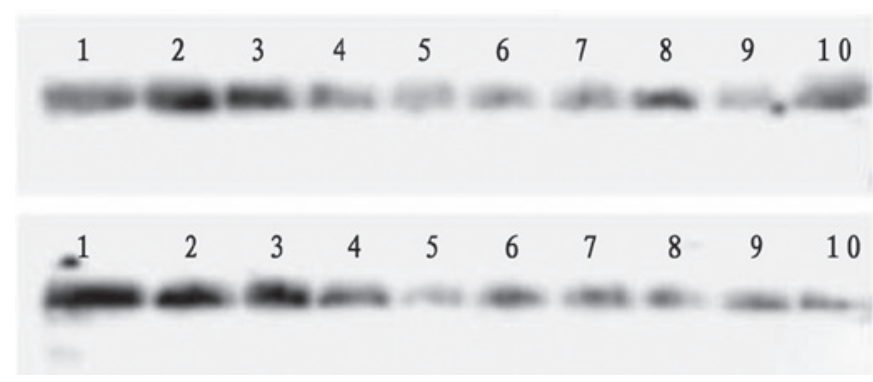

Figure 5. Western blot analysis of platelet-derived growth factor-B (PDGF-B) protein at various time points following injection of lipopolysaccharide (LPS). Upper row depicts the control group from left to right as $1-5(2,6,12$, 24 and $72 \mathrm{~h})$ and the glutamine (Gln) treatment group as 6-10 $(2,6,12,24$ and $72 \mathrm{~h})$. Lower row depicts the control group from left to right as 1-5 (2, 6, $12,24$ and $72 \mathrm{~h})$ and the LPS group as 6-10 (2, 6, 12, 24 and $72 \mathrm{~h})$.

LPS injection and decreased further at $24 \mathrm{~h}$ post-injection. Gln-treated tissues displayed increasing HSP70 levels at 2 and $6 \mathrm{~h}$ after LPS injection and did not exhibit subsequent decreases in HSP70. Compared to the LPS group, the expression levels of HSP70 were significantly higher in the Gln treatment group at all examined time points between 2 and $24 \mathrm{~h}$ post-injection.

Immunolocalization of PDGF-B and PDGFR- $\beta$ in brain tissue. Cytoplasmic PDGF-B immunoreactivity was observed in the cortical cells of control rats (Fig. 4A). In the LPS group at 2 and $6 \mathrm{~h}$ post-injection, PDGF-B immunoreactivity was lightly positive. At $72 \mathrm{~h}$ after injection, LPS group samples displayed markedly positive PDGF-B immunoreactivity in the nucleoli of cortical neurons (Fig. 4B). PDGF-B immunoreactivity was observed at these same time points in the Gln treatment group (Fig. 4C).

PDGFR- $\beta$ immunoreactivity was slightly positive in the membranes of control cortical neurons (Fig. 4D). Conversely, PDGFR- $\beta$ immunoreactivity was abolished from 2 to $24 \mathrm{~h}$

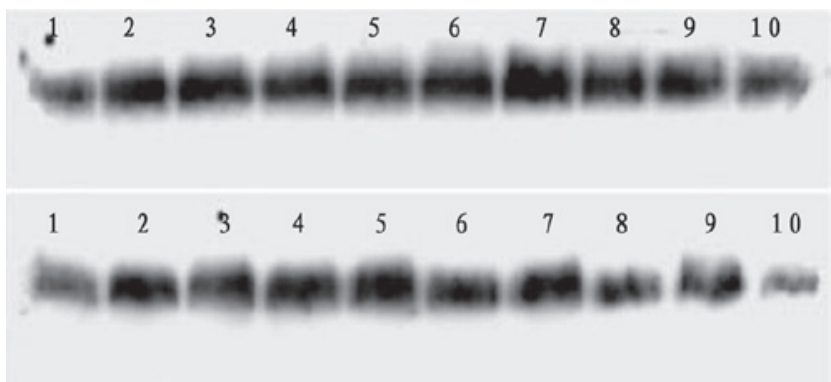

Figure 6 . Western blot analysis of PDGF receptor- $\beta$ (PDGFR- $\beta$ ) protein at various time points following injection of lipopolysaccharide (LPS). Upper row depicts the control group from left to right as 1-5 (2, 6, 12, 24 and $72 \mathrm{~h})$ and the treatment group as 6-10 $(2,6,12,24$ and $72 \mathrm{~h})$. Lower row depicts the control group from left to right as $1-5(2,6,12,24$ and $72 \mathrm{~h})$ and the LPS group as 6-10 $(2,6,12,24$ and $72 \mathrm{~h})$.

after injection of LPS in both the LPS and Gln treatment groups. In the LPS group at $72 \mathrm{~h}$ post-injection, PDGFR- $\beta$ weakly stained neurons (Fig. 4E), whereas PDGFR- $\beta$ staining was moderately positive in Gln-treated neurons at the same time points (Fig. 4F).

Western blot analysis of PDGF-B protein following LPS injection. PDGF-B protein expression decreased from 2 to $24 \mathrm{~h}$ in the LPS group post-injection and returned to control levels at $72 \mathrm{~h}$ post-injection (Fig. 5, Table II). The decrease in PDGF-B in the Gln treatment group was less pronounced than that in the LPS group (Fig. 5, 2 and 12 h), and PDGF-B significantly increased in the treatment group $72 \mathrm{~h}$ post-injection. Compared to the LPS group, the expression levels of PDGF-B were significantly increased in the treatment group 2, 12 and $72 \mathrm{~h}$ post-injection.

Western blot analysis of PDGFR- $\beta$ protein following LPS injection. PDGFR- $\beta$ protein expression increased $2 \mathrm{~h}$ postinjection in the LPS group, whereas it progressively decreased 
Table II. Semiquantitative expression of PDGF-B in LPS and Gln treatment groups $(\bar{\chi} \pm \mathrm{s}, \mathrm{n}=3)$.

\begin{tabular}{|c|c|c|c|c|c|}
\hline Group & $2 \mathrm{~h}$ & $6 \mathrm{~h}$ & $12 \mathrm{~h}$ & $24 \mathrm{~h}$ & $72 \mathrm{~h}$ \\
\hline LPS & $0.35 \pm 0.02$ & $0.42 \pm 0.02$ & $0.38 \pm 0.03$ & $0.63 \pm 0.03$ & $1.08 \pm 0.02$ \\
\hline Gln & $0.45 \pm 0.03$ & $0.37 \pm 0.03$ & $0.62 \pm 0.02$ & $0.66 \pm 0.02$ & $1.94 \pm 0.05$ \\
\hline $\mathrm{T}$ & 4.81 & 2.40 & 11.54 & 1.44 & 27.65 \\
\hline P-value & $<0.01$ & $>0.05$ & $<0.01$ & $>0.05$ & $<0.01$ \\
\hline
\end{tabular}

PDGF-B, platelet-derived growth factor-B; LPS, lipopolysaccharide; Gln, glutamine.

Table III. Semiquantitative expression of PDGFR- $\beta$ in LPS and Gln treatment groups $(\bar{\chi} \pm s, n=3)$.

\begin{tabular}{|c|c|c|c|c|c|}
\hline Group & $2 \mathrm{~h}$ & $6 \mathrm{~h}$ & $12 \mathrm{~h}$ & $24 \mathrm{~h}$ & $72 \mathrm{~h}$ \\
\hline LPS & $1.30 \pm 0.04$ & $1.02 \pm 0.03$ & $0.78 \pm 0.02$ & $0.80 \pm 0.03$ & $0.36 \pm 0.04$ \\
\hline Gln & $1.59 \pm 0.03$ & $1.20 \pm 0.03$ & $0.97 \pm 0.03$ & $0.98 \pm 0.02$ & $0.77 \pm 0.03$ \\
\hline $\mathrm{T}$ & 10.07 & 7.35 & 9.13 & 8.65 & 10.05 \\
\hline P-value & $<0.01$ & $<0.01$ & $<0.01$ & $<0.01$ & $<0.01$ \\
\hline
\end{tabular}

PDGFR- $\beta$, PDGF receptor- $\beta$; LPS, lipopolysaccharide; Gln, glutamine.

from 12 to $72 \mathrm{~h}$ post-injection (Fig. 6, Table III). In the Gln treatment group, a greater increase in PDGFR- $\beta$ protein expression was observed from 2 to $6 \mathrm{~h}$ post-injection. In addition, the late-stage decrease in PDGFR- $\beta$ was less pronounced than that of the LPS group. Compared with the LPS group, the expression levels of PDGFR- $\beta$ were significantly higher in the Gln treatment group at each time point.

\section{Discussion}

The present study demonstrates that the apoptotic process occurs in brain cells subjected to experimental endotoxemia and that apoptosis is suppressed to a certain extent by administration of Gln prior to endotoxemia. NF- $\kappa \mathrm{B}$ was detected in brain cells undergoing endotoxemic stress; this transcription factor was suppressed by administration of Gln. Pretreatment with Gln prevented endotoxemia-associated suppression of HSP70. Finally, Gln ameliorated the downregulation in PDGF-B and PDGFR- $\beta$ proteins that occurred in untreated brain cells undergoing endotoxemia.

Apoptosis is a process of gene-regulated cell death that involves special biochemical and morphological manifestations. Morphologically, apoptosis is characterized by pyknosis with chromatin condensation, such that chromatin forms crescent bodies within intact nuclear membranes. The mechanism of apoptosis induced by endotoxin injection has been postulated as Akt pathway activation (13), Bcl-2 family induction (14) or release of inflammatory cytokines (15). In concordance with a previous study that reported brain cell apoptosis upon systemic induction of inflammation (16), our study observed enhanced apoptosis in response to LPS injection. Gln pre-administration protected against brain cell apoptosis, supporting the theory that Gln may be effective in reducing endotoxemic brain damage.
$\mathrm{NF}-\kappa \mathrm{B}$ is one of the most important mediators of stress and inflammatory gene expression. Activation of NF- $\mathrm{B}$ plays an important role in the CNS, particularly in the neopallium neocortex, olfactory bulb, amygdaloid nucleus and hippocampus. Chen and other researchers discovered that $N F-\kappa B$ is activated immediately upon injury, peaking at $12 \mathrm{~h}$. A separate study reported that 2-6 $\mathrm{h}$ after intraperitoneal injection with endotoxin, NF- $\kappa \mathrm{B}$ is activated in neurons of the pallium; after $12 \mathrm{~h}, \mathrm{NF}-\mathrm{\kappa B}$ is activated in astrocyte nuclei surrounding denatured neurons. In premature rats subjected to endotoxemia, the activation of NF- $\kappa \mathrm{B}$ is strongly associated with neuronal survival in the early stages of brain injury and inflammation $(17,18)$. HSP72 may play a major role in attenuating the inflammatory response following Gln administration in sepsis (19). The present study demonstrated that the expression of HSP70 is suppressed during endotoxemia and that this effect could be avoided by Gln pretreatment.

The expression of PDGF-B is capable of relieving hypoxemic brain injury after shock. In macaques with simian immunodeficiency virus encephalitis, the expression of PDGF-B mRNA increased in the brains (20). Previous studies demonstrated that endogenous PDGF-B plays important roles in healing after trauma, synapse regeneration and functional recovery (21). We detected PDGF-B expression in the cytoplasm of cortical neurons and PDGFR- $\beta$ expression in the cell membranes of cortical neurons. Post-injection with LPS, PDGF-B expression decreased significantly at 2, 12 and $72 \mathrm{~h}$. At $72 \mathrm{~h}$, PDGF-B expression recovered, indicating that PDGF-B is capable of protecting nerves by regulating neuroglia cell differentiation following brain injury. PDGFR- $\beta$ expression is increased early following experimental endotoxemia, indicating that organisms may sustain and nourish cells by expressing PDGFR- $\beta$ in the early stages of infectious stress. 
The mechanism by which PDGF and its $\beta$ receptor protect nerve cells may involve the following: (i) Prior PDGF exposure protects neurons against excitotoxicity (22); (ii) PDGF-B may increase neuron viability by inhibiting NMDA receptor activation, thereby inhibiting excessive influx of $\mathrm{Ca}^{2+}$; (iii) PDGF may promote the activity of superoxide dismutase and glutathione reductase and protect the nerves (23); (iv) activation of PI-3 may inhibit the apoptosis of nerve cells (24); (v) PDGF-B is necessary for survival, and induction of PDGF-B can increase cell migration and neural differentiation by basic fibroblast growth factor as well as decrease other open channels (25), causing prolonged suppression of the NMDA receptor (26). In the present study, expression of PDGF-B decreased during experimental sepsis for 2-24 h. By 72 h, PDGF-B expression recovered, but did not reach the same levels as in the Gln group. The expression of PDGF-B and PDGF in neurons of the pallium in the early and late stages of sepsis in premature rats, suggest that the mechanism of protecting brain injury may be related to these factors.

In conclusion, the present study demonstrates that Gln administration modifies the process of endotoxemic brain damage in an experimental model of sepsis in young rats. Although the exact mechanism of Gln mediation in this process has not been elucidated, the enhanced expression of HSP70 and the preservation of the PDGF signal transduction system are likely to be involved in the protective effect of Gln.

\section{References}

1. Wischmeyer PE, Kahana M, Wolfson R, Ren H, Musch MM and Chang EB: Glutamine induces heat shock protein and protects against endotoxin shock in the rat. J Appl Physiol 90: 2403-2410, 2001.

2. Opie LH: Reperfusion injury and its pharmacologic modification. Circulation 80: 1049-1062, 1989.

3. Ribeiro SP, Villar J and Slutsky AS: Induction of the stress response to prevent organ injury. New Horiz 3: 301-311, 1995.

4. De Maio A: Heat shock proteins: facts, thoughts, and dreams. Shock 11: 1-12, 1999.

5. Chu EK, Ribeiro SP and Slutsky AS: Heat stress increases survival rates in lipopolysaccharide-stimulated rats. Crit Care Med 25: 1727-1732, 1997.

6. Stice JP and Knowlton AA: Estrogen, NFkappaB, and the heat shock response. Mol Med 14: 517-527, 2008.

7. Voegeli TS, Wintink AJ, Chen Y and Currie RW: Heat shock proteins 27 and 70 regulating angiotensin II-induced NF-kappaB a possible connection to blood pressure control? Appl Physiol Nutr Metab 33: 1042-1049, 2008.

8. Yoo CG, Lee S, Lee CT, Kim YW, Han SK and Shim YS: Antiinflammatory effect of heat shock protein induction is related to stabilization of I kappa B alpha through preventing I kappa B kinase activation in respiratory epithelial cells. J Immunol 164 5416-5423, 2000.

9. Rogister B, Ben-Hur T and Dubois-Dalcq M: From neural stem cells to myelinating oligodendrocytes. Mol Cell Neurosci 14 287-300, 1999.

10. Dubois-Dalcq M and Murray K: Why are growth factors important in oligodendrocyte physiology? Pathol Biol (Paris) 48 $80-86,2000$.
11. Morioka I, Tsuneishi S, Takada S and Matsuo M: PDGF-alpha receptor expression following hypoxic-ischemic injury in the neonatal rat brain. Kobe J Med Sci 50: 21-30, 2004.

12. Liu JC, Wang HT and Wang W: Protective effects of alanylglutamine on acute lung injury induced by lipopolysaccharide in rats. Zhong Nan Da Xue Xue Bao Yi Xue Ban 33: 1095-1100, 2008.

13. Jacob A, Hensley LK, Safratowich BD, Quigg RJ and Alexander JJ: The role of the complement cascade in endotoxininduced septic encephalopathy. Lab Invest 87: 1186-1194, 2007.

14. Caruso C, Durand D, Schiöth HB, Rey R, Seilicovich A and Lasaga M: Activation of melanocortin 4 receptors reduces the inflammatory response and prevents apoptosis induced by lipopolysaccharide and interferon-gamma in astrocytes. Endocrinology 148: 4918-4926, 2007.

15. Islam Z, Amuzie CJ, Harkema JR and Pestka JJ: Neurotoxicity and inflammation in the nasal airways of mice exposed to the macrocyclic trichothecene mycotoxin roridin a: kinetics and potentiation by bacterial lipopolysaccharide coexposure. Toxicol Sci 98: 526-541, 2007.

16. Semmler A, Okulla T, Sastre M, Dumitrescu-Ozimek L and Heneka MT: Systemic inflammation induces apoptosis with variable vulnerability of different brain regions. J Chem Neuroanat 30: 144-157, 2005.

17. Chen G, Shi J, Hu Z and Hang C: Inhibitory effect on cerebral inflammatory response following traumatic brain injury in rats: a potential neuroprotective mechanism of $\mathrm{N}$-acetylcysteine. Mediators Inflamm 2008: 716458, 2008.

18. Chen NJ, Chio II, Lin WJ, et al: Beyond tumor necrosis factor receptor: TRADD signaling in toll-like receptors. Proc Natl Acad Sci USA 105: 12429-12434, 2008.

19 Wang XM, Liang MF, Yuan Y and Jiang W: The different effects of glutamine on macrophage cytokines release in vivo and in vitro. Zhongguo Wei Zhong Bing Ji Jiu Yi Xue 20: 456-460, 2008 (In Chinese).

20. Potula R, Dhillion N, Sui Y, Zien CA, Funa K, Pinson D, Mayo MS, Singh DK, Narayan O and Buch S: Association of platelet-derived growth factor-B chain with simian human immunodeficiency virus encephalitis. Am J Pathol 165: 815-824, 2004.

21. Xiyang YB, Liu S, Liu J, Hao CG, Wang ZJ, NI W, Wang XY and Wang TH: Roles of platelet-derived growth factor-B expression in the ventral horn and motor cortex in the spinal cord-hemisected rhesus monkey. J Neurotrauma 26: 275-287, 2009.

22. Tseng HC and Dichter MA: Platelet-derived growth factor-BB pretreatment attenuates excitotoxic death in cultured hippocampal neurons. Neurobiol Dis 19: 77-83, 2005.

23. Iantomasi T, Favilli F, Catarzi S and Vincenzini MT: GSH role on platelet-derived growth factor receptor tyrosine phosphorylation induced by $\mathrm{H}_{2} \mathrm{O}_{2}$. Biochem Biophys Res Commun 280: 1279-1285, 2001

24. Peng F, Dhillon N, Callen S, Yao H, Bokhari S, Zhu X, Baydoun $\mathrm{HH}$ and Buch S: Platelet-derived growth factor protects neurons against gp120-mediated toxicity. J Neurovirol 14: 62-72, 2008.

25. Ishii Y, Matsumoto Y, Watanabe R, Elmi M, Fujimori T, Nissen J, Cao Y, Nabeshima Y, Sasahara M and Funa K: Characterization of neuroprogenitor cells expressing the PDGF beta-receptor within the subventricular zone of postnatal mice. Mol Cell Neurosci 37: 507-518, 2008.

26. Beazely MA, Weerapura M and Macdonald JF: Abelson tyrosine kinase links PDGFbeta receptor activation to cytoskeletal regulation of NMDA receptors in CA1 hippocampal neurons. Mol Brain 1: 20,2008. 